\title{
Monitoring of the invasion of Spartina alterniflora from 1985 to 2015 in Zhejiang Province, China
}

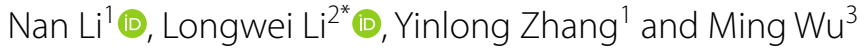

\begin{abstract}
Background: Spartina alterniflora is an invasive plant on the coast of China that replaces native vegetation and has a serious negative impact on local ecosystems. Monitoring the spatial distribution of S. alterniflora and its changes over time can reveal its expansion mechanism, which is crucial for the management of coastal ecosystems. The purpose of this study was to map the distribution of S. alterniflora in Zhejiang Province from 1985 to 2015 using a time series of Landsat TM/OLI images and analyze the temporal and spatial patterns of expansion of this species.

Results: After analyzing the distribution of coastal vegetation, the vegetation index was calculated based on Landsat images for 4 years $(1985,1995,2005$ and 2015). According to a threshold determined based on expert knowledge, the distribution of S. alterniflora in Zhejiang Province was extracted, and the temporal and spatial changes in the distribution of S. alterniflora were analyzed. The classification accuracy was $90.3 \%$. S. alterniflora has expanded rapidly in recent decades after being introduced into southern Zhejiang. Between 1985 and 2015, S. alterniflora increased its area of distribution by $10,000 \mathrm{hm}^{2}$, and it replaced native vegetation to become the most abundant halophyte in tidal flats. Overall, S. alterniflora expanded from south to north over the decades of the study, and the fastest expansion rate was $463.64 \mathrm{hm}^{2} /$ year, which occurred between 1995 and 2005. S. alterniflora was widely distributed in the tidal flats of bays and estuaries and expanded outward as sediment accumulated.
\end{abstract}

Conclusions: This study reveals the changes over time in S. alterniflora cover in Zhejiang and can contribute to the control and management of this invasive plant.

Keywords: Dynamic change, Expert knowledge, Invasive plants, Landsat images, Spartina alterniflora

\section{Background}

Spartina alterniflora Loisel. is a perennial halophyte that is native to the Atlantic and Gulf coasts of North America and predominates in local salt marshes [1]. S. alterniflora is generally considered beneficial in ecological restoration because of its well-developed underground structure, high salt tolerance, high reproductive capacity and rapid growth [2]. For this reason, in December 1979, S.

\footnotetext{
*Correspondence: xflilongwei@126.com

${ }^{2}$ School of Environmental \& Resource Sciences, Zhejiang Agriculture and Forestry University, Hangzhou 311300, China

Full list of author information is available at the end of the article
}

alterniflora was intentionally introduced as an ecological engineering species into China for sediment accumulation, land reclamation and saline soil amelioration [3].

Experiments have shown that S. alterniflora can perform ecological functions and provide economic benefits $[2,4-6]$. Coastal stabilization and land reclamation are the most important ecological functions of this species. A trial planting of S. alterniflora was employed to solve river-shore crumbling near a sluice in Zhejiang Province in 1986. The planting successfully solved this problem, costing only 800 Yuan, and withstood typhoons and floods [2]. The S. alterniflora marsh on the canal bank prevented more than $100,000 \mathrm{~m}^{3}$ of sediment per year 
from migrating downstream [3]. In addition, Shen et al. [7] proved the efficacy of this plant for saline soil amelioration. Furthermore, S. alterniflora is used as animal fodder and fish feed $[2,8,9]$ and can be used to produce green manure and biomineral liquids [1].

Since its introduction, S. alterniflora has greatly expanded in distribution in the coastal salt marshes of China $[1,10]$. An increasing number of studies have demonstrated that although this exotic species can be beneficial, it has negative impacts on native coastal ecosystems [11-14]. Once established, S. alterniflora quickly expands on bare beaches and competes with native plants, invading their habitats and replacing them. Areas of Scirpus mariqueter Wang et Tang and Phragmites australis Trin. ex Steud. and young mangrove swamps have been invaded by $S$. alterniflora. Research shows that the species richness of benthic macroinvertebrates in S. alterniflora swamps is reduced because its invasion alters the physicochemical properties of the sediment [15]. Some endangered birds are threatened because the density of $S$. alterniflora communities is too high and the altered habitats are no longer suitable for them [16]. Therefore, the habitats of native plants, birds and benthic animals are affected by S. alterniflora, and biodiversity is reduced [17, 18]. In addition, the invasion of S. alterniflora impedes the development of local aquaculture and tourism and hinders water-based transportation $[19,20]$. The significant negative impacts of this species have far exceeded its ecological functions and economic benefits [12, 21, 22]. S. alterniflora was listed as one of the top 16 invasive alien species by the State Environmental Protection Administration of China in $2003[1,23]$.

Biological invasion has a strong influence on Earth's ecosystems and is considered one of the three most pressing environmental issues [24-26]. S. alterniflora threatens local ecosystems and causes extremely large losses to the regional economy [11]. At present, from Guangxi Province $\left(21^{\circ} 33^{\prime} \mathrm{N}, 108^{\circ} 08^{\prime} \mathrm{E}\right)$ to Liaoning Province $\left(40^{\circ} 20^{\prime} \mathrm{N}, 122^{\circ} 35^{\prime} \mathrm{E}\right)$, S. alterniflora can be found in most of China's coastal areas [10, 27]. According to the Marine Environment Quality Bulletin of China, this species invaded 12,400 ha of China's coastal areas in 2006. Jianbo $\mathrm{Lu}$ [1] stated that it covered a total area of 34,178 ha in 2012. Hence, the invasion of S. alterniflora has become a hot topic for ecologists and biologists at home and abroad.

Over the years, scholars have conducted many studies on the invasion of S. alterniflora in China's coastal areas. However, there are few studies on the monitoring of changes in S. alterniflora distribution, with most such studies limited to monitoring the distribution of S. alterniflora in a given year. The lack of long-term sequential monitoring of $S$. alterniflora not only limits our understanding of the invasion mechanism but also restricts the decision-making of government departments. To better understand the expansion mechanism of $S$. alterniflora and prevent its further invasion, it is necessary to map its distribution and monitor its dynamic changes. Therefore, this study employed a time series of Landsat Thematic Mapper (TM)/Operational Land Imager (OLI) images to monitor the dynamic changes in S. alterniflora in the coastal areas of Zhejiang Province, China. Specifically, the spatial distribution of S. alterniflora in Zhejiang Province from 1985 to 2015 was mapped, the spatial and temporal heterogeneities of S. alterniflora expansion were analyzed, and the changes in S. alterniflora in bays and estuaries were analyzed. This study documents the temporal and spatial changes in S. alterniflora invasion on the eastern coast of China, providing important data for the ecological study of $S$. alterniflora.

\section{Methods}

\section{Study area}

Zhejiang Province is located in eastern China (Fig. 1a). It has a subtropical monsoon climate with moderate annual temperatures and abundant sunshine and rainfall. Zhejiang has abundant marine resources, with a coastline of $6486.24 \mathrm{~km}$, accounting for $20.3 \%$ of China's coastline. According to the second wetland resource survey, the tidal flats are the largest natural wetland in the province, covering $1548.86 \mathrm{~km}^{2}$. The tidal flats are mainly distributed in Hangzhou Bay, Sanmen Bay and Yueqing Bay. In 1983, S. alterniflora was first planted in the tidal flats of Yuhuan County and then introduced to other places along the coast. Over the past 30 years, S. alterniflora has rapidly expanded and become the main salt marsh vegetation along the coast of Zhejiang Province.

\section{Data collection and preprocessing}

The data collected in this study included remote sensing images, vector data such as administrative boundaries, field survey data and literature data. Remote sensing is an effective tool for monitoring changes in Earth's surface and is suitable for coastal wetland monitoring and vegetation monitoring [27-30]. Since 1972, NASA has launched a number of Landsat series satellites, which are the most commonly used remote sensing data sources. Twenty-six scenes of Landsat TM/OLI images were obtained from the U.S. Geological Survey Global Visualization data server (https://glovis.usgs.gov/app). The principles of remote sensing image acquisition included (1) selecting images taken between May and November, which is the growth season of S. alterniflora and (2) selecting highquality images without cloud cover. Table 1 summarizes 


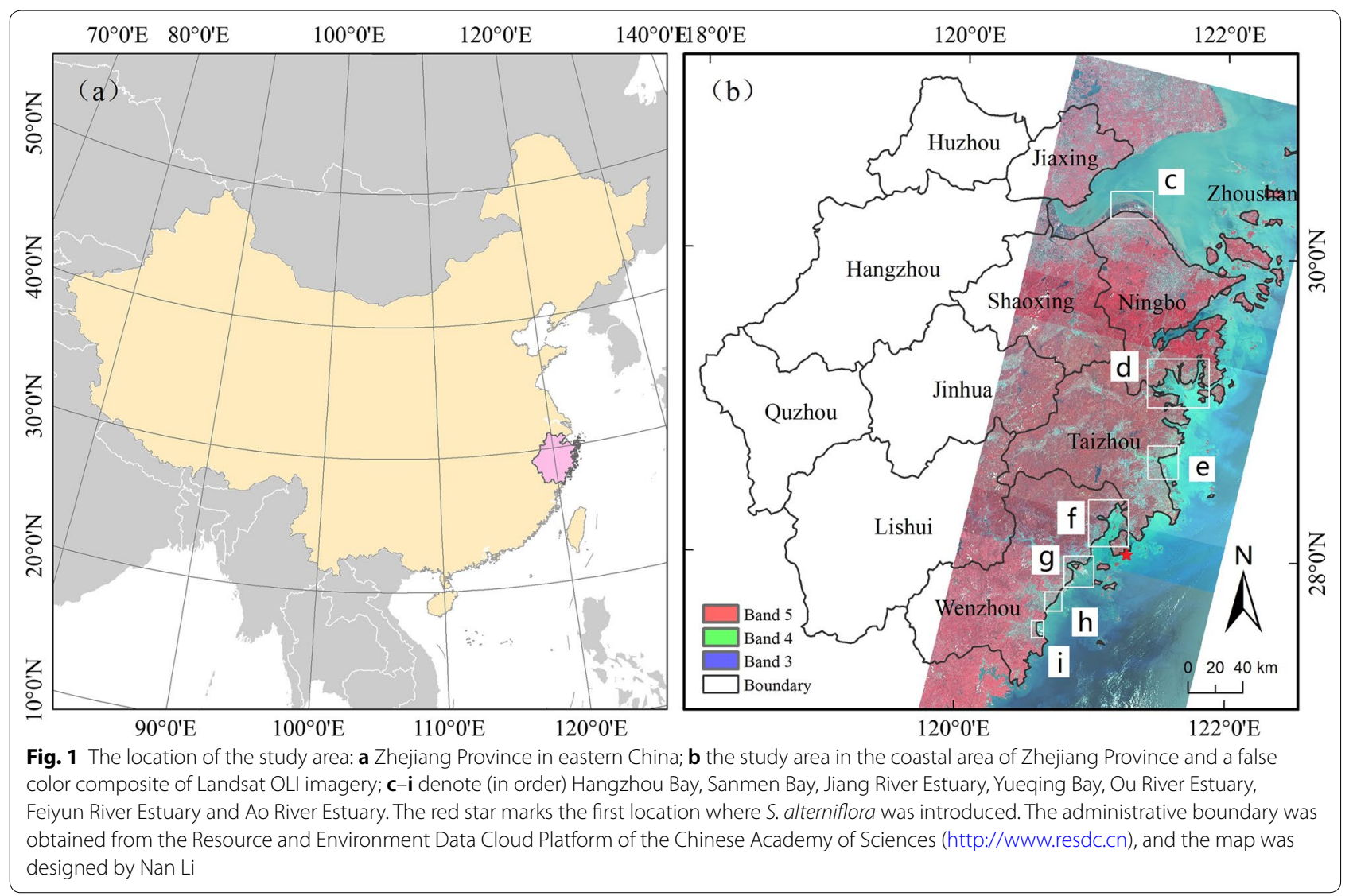

Table 1 Dates and sensors for the remote sensing imagery used in this study

\begin{tabular}{lllll}
\hline Year & \multicolumn{3}{l}{ Path/row } & \multirow{2}{*}{ Sensors } \\
\cline { 2 - 4 } & $\mathbf{1 1 8 / 3 9}$ & $\mathbf{1 1 8 / 4 0}$ & $\mathbf{1 1 8 / 4 1}$ & \\
\hline 1985 & 1985.07 .15 & 1984.05 .09 & 1984.04 .23 & TM \\
& & 1985.06 .29 & 1986.05 .31 & \\
1995 & 1995.08 .12 & 1995.03 .05 & 1995.08 .12 & TM \\
& 1995.11 .16 & 1995.11 .16 & 1995.11 .16 & \\
2005 & 2005.06 .04 & 2005.06 .04 & 2005.06 .04 & TM \\
& 2005.11 .27 & 2005.11 .27 & 2005.11 .27 & \\
2015 & 2014.11 .04 & 2014.11 .04 & 2014.11 .04 & OLI \\
& 2015.08 .03 & 2015.08 .03 & 2015.08 .03 & \\
& 2016.07 .20 & 2016.07 .20 & 2016.07 .20 & \\
\hline
\end{tabular}

the acquisition dates and sensor types of the remote sensing images used in this study.

From May to November in 2015, field investigations were conducted in coastal areas of Zhejiang Province. The S. alterniflora community as determined visually in the field was marked on a Google Earth map with polygons. In addition, the positions of S. alterniflora plants were recorded using GIStar 710, a hand-held geographic positioning system device (South Surveying \& Mapping Instrument Co., Guangzhou, China). Field surveys provide important location information for visual interpretation and classification of remote sensing images. A large number of Chinese and English research papers and statistical yearbooks were reviewed to obtain information about the distribution of S. alterniflora. In addition, detailed consultations were conducted with local people through field investigations.

All remote sensing images were preprocessed with ENVI 5.3 software, including radiometric calibration, atmospheric correction and image-to-image registration. The Fast Line-of-Site Atmospheric Analysis of Spectral Hypercubes [31] method was used for atmospheric correction. The latest image was used as the reference image to register images from other periods. More than 30 control points were selected for each registration, and the root mean square error was less than 0.5 pixels. All images were under Universal Transverse Mercator 50 (UTM-50) projection systems. 


\section{Extracting the distribution of S. alterniflora}

Based on literature surveys and the field investigations, it was determined that $S$. alterniflora grows only in intertidal zones with high salinity and does not exist inland. In addition, there are dikes along the coast of Zhejiang Province that can prevent waves, which form an obvious artificial boundary between tidal flats and inland areas. $S$. alterniflora (Fig. 2c), S. mariqueter (Fig. 2d), mud beach (Fig. 2e) and sea water (Fig. 2f) are located outside the dikes, and aquaculture ponds (Fig. 2a) and farmland (Fig. 2b) are located inside the dikes. The coastline was used as a baseline to obtain a $2 \mathrm{~km}$ buffer area outside the dikes. In this area, the main plants are only $S$. alterniflora and S. mariqueter, facilitating the identification of $S$. alterniflora [27].

The growth environments and spectral characteristics of $S$. alterniflora and S. mariqueter are quite different. S. alterniflora grows vigorously and has high coverage, showing typical vegetation spectral characteristics. The plants of S. mariqueter are low, sparse, and often submerged by tides, thus exhibiting mixed spectral characteristics of vegetation, water and soil. The normalized difference vegetation index (NDVI), which can express vegetation characteristics, was calculated. Analysis revealed that during the growing season, the NDVI of $S$. alterniflora was higher than that of $S$. mariqueter, which was quite low. Therefore, according to their NDVI differences and previous studies [27, 29], an appropriate threshold was selected, and decision tree classification was used to extract S. alterniflora. Then, Google Earth images were used for postprocessing, unambiguously misclassified land types were modified, and the final spatial distribution of $S$. alterniflora was obtained. Images from 2010 and other periods were processed in the same way. According to the field survey, 300 verification points were randomly selected for verification, a confusion matrix was used to evaluate the performance of the classification, and overall accuracy was used to assess the classification accuracy.

\section{Detecting the change in S. alterniflora distribution}

After extracting S. alterniflora from all images by ENVI 5.3 software, a distribution thematic map was constructed using ArcGIS 10.2 software, and the distribution changes were analyzed using the overlay function. The area of S. alterniflora within the administrative area of each city in each period was determined using ArcGIS 10.2 software. To better understand the expansion of $S$. alterniflora, based on the classification results of the previous step, the change in S. alterniflora was detected. In this study, the percentage (\%) of the area and total area of $S$. alterniflora in different regions were calculated for various years. The total expansion area per decade was calculated, and the annual expansion area was defined as $\left(\mathrm{X}_{\mathrm{j}}-\mathrm{X}_{\mathrm{i}}\right) /(\mathrm{j}-\mathrm{i})$, where $\mathrm{X}_{\mathrm{i}}$ and $\mathrm{X}_{\mathrm{j}}$ are the areas of $S$. alterniflora in the prior year $\mathrm{i}$ and the subsequent year $\mathrm{j}$, respectively.

The present study focused on bay and estuary areas to explore the expansion patterns of S. alterniflora in different areas along the coast of Zhejiang Province. Bays

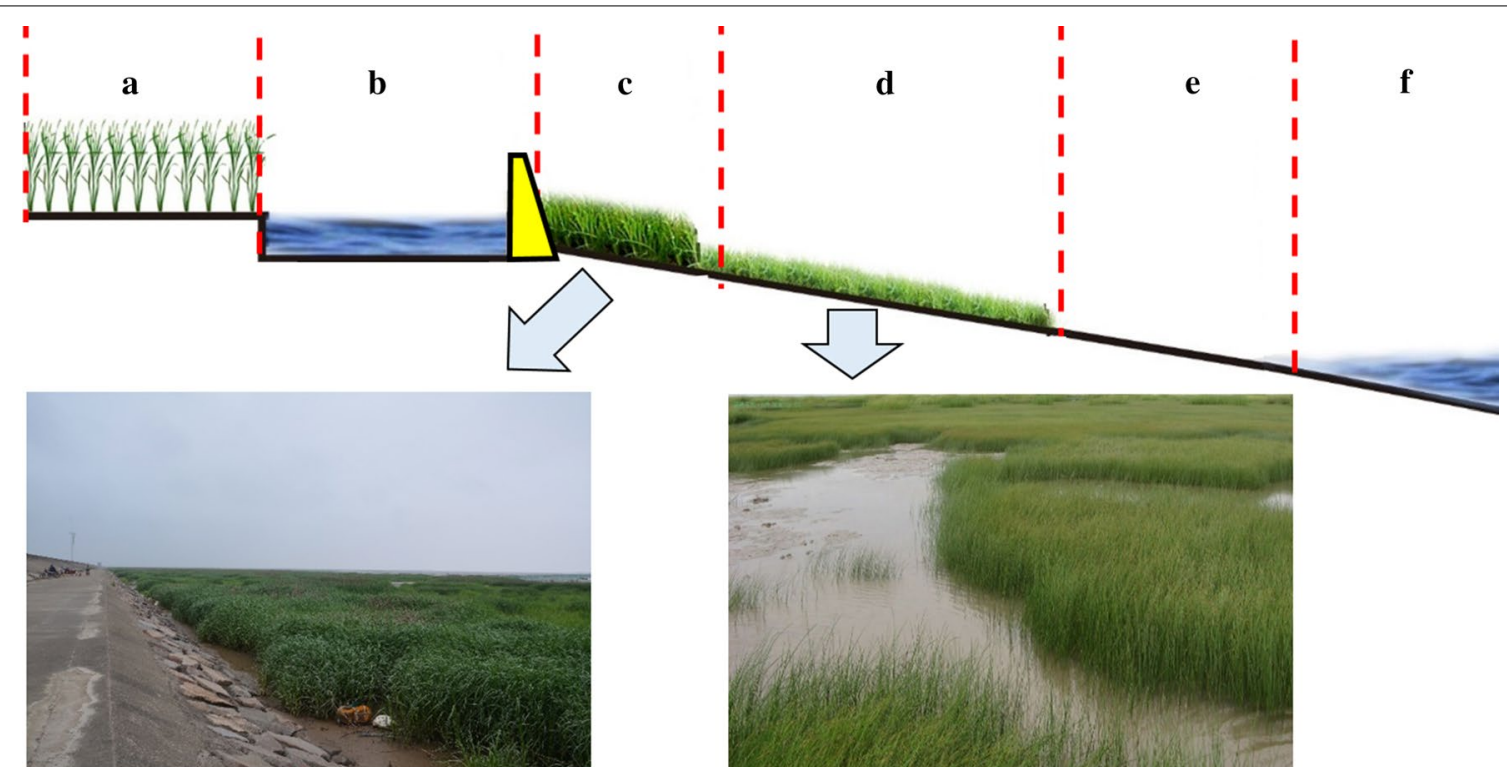

Fig. 2 Different land types and main vegetation along the coast. a-f denote (in order) aquaculture ponds, farmland, Spartina alterniflora, Scirpus mariqueter, mud beach and sea water. The yellow trapezoid is a dike 
are typically surrounded by land on three sides, exhibiting a U-shape or arc shape. The bays in Zhejiang mainly include Hangzhou Bay, Yueqing Bay and Sanmen Bay (Fig. 1). An estuary is the area where the river enters the sea, typically exhibiting an open, fan-shaped area and significant tidal phenomenon. The main estuaries in Zhejiang Province are Jiang River Estuary, Ou River Estuary, Feiyun River Estuary and Ao River Estuary (Fig. 1).

\section{Results}

Spatial distribution of S. alterniflora in Zhejiang Province

According to the field survey data, the classification results were verified, and the confusion matrix was calculated. The results showed that the overall accuracy was $90.3 \%$, and the kappa coefficient was 0.91 , meeting the research requirements. In 2015, S. alterniflora was estimated to cover more than $10,000 \mathrm{hm}^{2}$, from the northernmost point (Jiaxing) to the southernmost point (Wenzhou) along the coastline (Fig. 3). The species was mainly concentrated in the bays, estuaries, and ports, such as Hangzhou Bay, Sanmen Bay, Yueqing Bay, Feiyun River Estuary, Ao River Estuary, and Xiangshan Port. There were fewer S. alterniflora plants on the islands.

Table 2 summarizes the area of $S$. alterniflora in the coastal areas of Zhejiang from 1985 to 2015. S. alterniflora was first introduced and planted on the southern coast of Zhejiang Province in 1983; it did not extensively expand and could not be identified from the Landsat imagery until 1985. This delay occurred because of the coarse spatial resolution $(30 * 30 \mathrm{~m})$ of the Landsat TM imagery and because vegetation with an area of less than $900 \mathrm{~m}^{2}$ could not be accurately identified from the images.

By 1995 , the area of S. alterniflora had expanded to $1827.63 \mathrm{hm}^{2}$, mainly concentrated in Wenzhou, with an area of $1096.74 \mathrm{hm}^{2}$, accounting for $60.01 \%$ of the total area. In 2005, the total area of S. alterniflora was 6464.07 $\mathrm{hm}^{2}$, and the species was mainly distributed in Ningbo, with an area of $3706.47 \mathrm{hm}^{2}$. By 2015, the area of $S$. alterniflora reached $10,038.15 \mathrm{hm}^{2}$, and the species was mainly distributed in Ningbo and Taizhou.

Spatial and temporal variability of S. alterniflora expansion S. alterniflora spread widely along the coast from 1985 to 2015 , with the area increasing by $10,000 \mathrm{hm}^{2}$ and an average annual growth area of $334.61 \mathrm{hm}^{2}$ (Table 3). From 1985 to 1995, the expansion of S. alterniflora was relatively slow, with an annual expansion area of 182.76 $\mathrm{hm}^{2}$. Then, it expanded extensively during the decade from 1995 to 2005, with an average annual growth area of $463.64 \mathrm{hm}^{2}$. After 2005, the growth rate decreased to $357.41 \mathrm{hm}^{2}$. S. alterniflora significantly damaged the composition of local ecosystems and the landscape structure. The local government used several methods to control its growth. After 2005, S. alterniflora was partially under control, and the annual expansion area was reduced to $357.41 \mathrm{hm}^{2}$.

The expansion of S. alterniflora exhibited spatial and temporal variability in different coastal areas. In the past 30 years, the area of S. alterniflora in Ningbo has increased the most, expanding by $5425.83 \mathrm{hm}^{2}$. In the middle decade, S. alterniflora had the fastest expansion rate of $313.7 \mathrm{hm}^{2}$ per year. S. alterniflora in Wenzhou grew fastest in the first decade and then expanded at a slower rate and experienced negative growth in the last decade. The expansion of S. alterniflora in Taizhou was severe, and the annual expansion area increased each year. The expansion trend of S. alterniflora in Jiaxing was similar to that in Wenzhou, and its expansion rate declined in the last decade. S. alterniflora had the smallest area in Zhoushan, but it had been increasing over the last 30 years.

\section{The expansion pattern of S. alterniflora in typical areas}

S. alterniflora had different expansion patterns in the bays and estuaries. Yueqing Bay (Fig. 4a) and Sanmen Bay (Fig. 4b) are typical semiclosed bays in the study area, which extend deep into the interior. The tidal range in the bay is wide, and the winds and waves in the bay are mild, which creates conditions suitable for the growth of $S$. alterniflora. In these areas, S. alterniflora was widely distributed in the tidal flats, and a small number of plants were distributed along the coastline.

Hangzhou Bay is a trumpet-shaped bay located at the mouth of the Qiantang River. The suspended sediment content in the area is quite high. Due to the special terrain of the bay, the ocean current runs northward, causing erosion on the north bank and siltation on the south bank. Studies have shown that the south bank of Hangzhou Bay has expanded by $9 \mathrm{~km}$ in the past three decades. As shown in Fig. 5, as the coastline expanded each year, S. alterniflora expanded correspondingly, and its area increased. In 1985, there was no S. alterniflora in the area (Fig. 5a); in 1995, a small number of S. alterniflora plants were located on the southeastern shore (Fig. 5b). In 2005, S. alterniflora was distributed in strips (Fig. 5c). In 2015, S. alterniflora was widely distributed (Fig. 5d).

Ou River Estuary, Feiyun River Estuary and Ao River Estuary are typical estuaries in the study area (Fig. 6). The sediment carried by the river accumulated on both sides of the estuaries; this accumulation, accompanied by highintensity artificial reclamation, led to coastline expansion each year. S. alterniflora was distributed along the coast of the estuary area and moved outwards each year. 

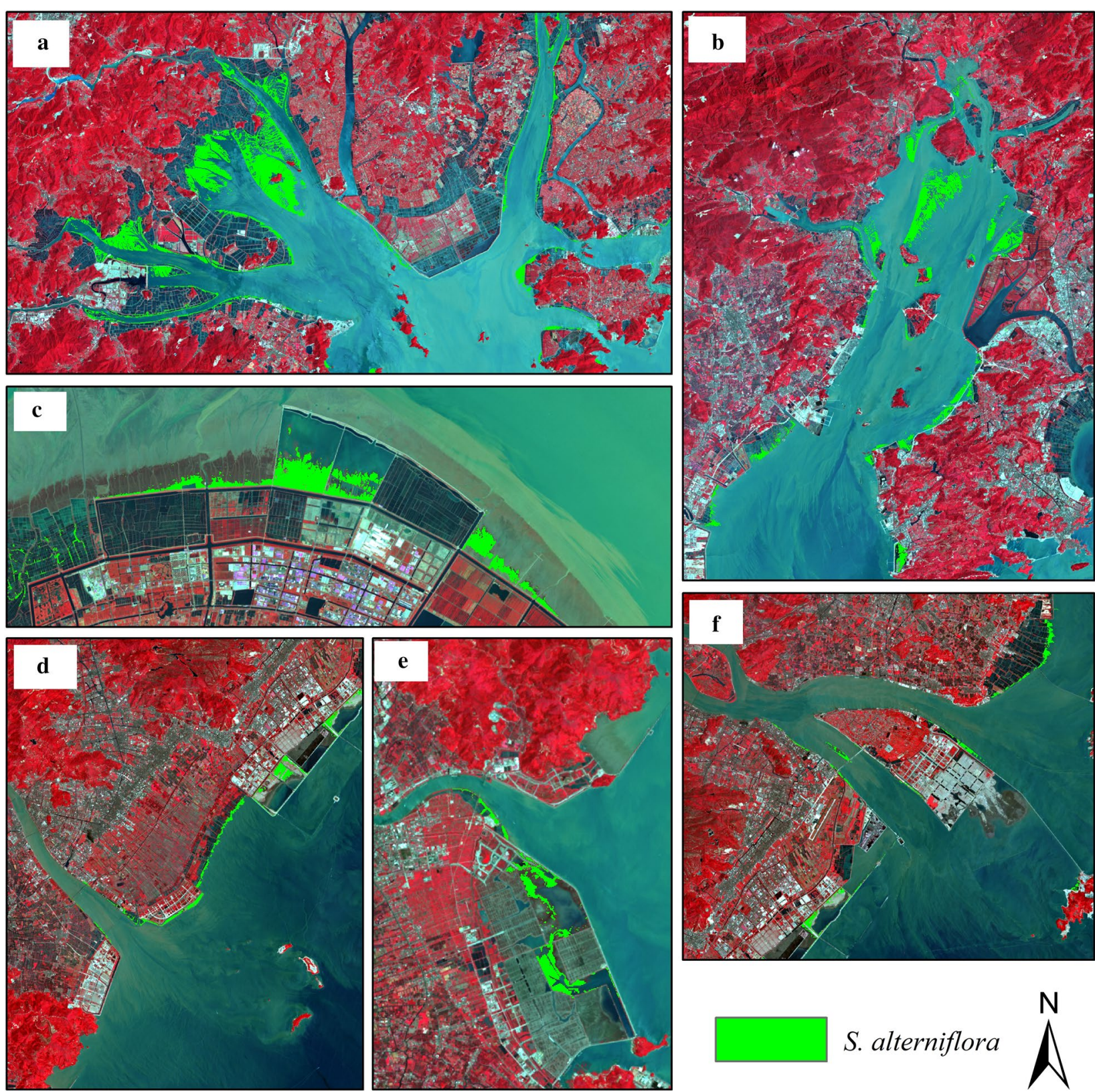

Fig. 3 The spatial distribution of S. alterniflora in Zhejiang Province in 2015. a Sanmen Bay in Taizhou; b Yueqing Bay in Wenzhou; c Hangzhou Bay in Ningbo; d Feiyun River Estuary in Wenzhou; e Ao River Estuary in Wenzhou; f Ou River Estuary in Wenzhou

\section{Discussion}

\section{Expansion dynamics of $S$. alterniflora in Zhejiang}

Spartina alterniflora was planted in Taizhou in 1983, introduced to Wenzhou in 1989, and expanded to the Zhejiang coast in 1991. In the following decades, $S$. alterniflora expanded rapidly along the coast of Zhejiang. S. alterniflora has the largest area and fastest expansion rate in the bay and estuary areas. The sediments produced by the slow currents in these areas favor the growth and expansion of S. alterniflora. In contrast, the islands in Zhoushan and other places have large tidal currents and few tidal flats [36], making them unsuitable for the settlement of S. alterniflora and thus able to support only a small area of the species. Zhejiang coastal cities are densely populated, and dikes were built along the coast to protect cities and farmland. Therefore, in contrast to the expansion of terrestrial plants, which expand from inland areas toward 
Table 2 Spartina alterniflora in Zhejiang Province from 1985 to 2015

\begin{tabular}{|c|c|c|c|c|c|c|c|c|}
\hline & \multicolumn{2}{|l|}{1985} & \multicolumn{2}{|l|}{1995} & \multicolumn{2}{|l|}{2005} & \multicolumn{2}{|l|}{2015} \\
\hline & $\mathrm{hm}^{2}$ & $\%$ & $\mathrm{hm}^{2}$ & $\%$ & $\mathrm{hm}^{2}$ & $\%$ & $\mathrm{hm}^{2}$ & $\%$ \\
\hline Zhoushan & - & - & - & - & 1.71 & 0.03 & 83.07 & 0.83 \\
\hline Jiaxing & - & - & 96.57 & 5.28 & 263.97 & 4.08 & 322.11 & 3.21 \\
\hline Ningbo & - & - & 569.52 & 31.16 & 3706.47 & 57.34 & 5425.83 & 54.05 \\
\hline Taizhou & - & - & 64.80 & 3.55 & 916.65 & 14.18 & 2760.03 & 27.50 \\
\hline Wenzhou & - & - & 1096.74 & 60.01 & 1575.27 & 24.37 & 1447.11 & 14.42 \\
\hline Zhejiang Province & - & - & 1827.63 & 100.00 & 6464.07 & 100.00 & $10,038.15$ & 100.00 \\
\hline
\end{tabular}

Table 3 Analysis of the expansion of S. alterniflora from 1985 to 2015

\begin{tabular}{|c|c|c|c|c|}
\hline \multirow[t]{2}{*}{ District } & \multicolumn{3}{|c|}{ Expanded area per 10 years $\left(\mathrm{hm}^{2}\right)$} & \multirow[t]{2}{*}{ 1985-2015 } \\
\hline & 1985-1995 & 1995-2005 & 2005-2015 & \\
\hline Zhoushan & 0.00 & 1.71 & 81.36 & 83.07 \\
\hline Jiaxing & 96.57 & 167.40 & 58.14 & 322.11 \\
\hline Ningbo & 569.52 & 3136.95 & 1719.36 & 5425.83 \\
\hline Taizhou & 64.80 & 851.85 & 1843.38 & 2760.03 \\
\hline Wenzhou & 1096.74 & 478.53 & -128.16 & 1447.11 \\
\hline Zhejiang Province & 1827.63 & 4636.44 & 3574.08 & $10,038.15$ \\
\hline \multirow[t]{2}{*}{ District } & \multicolumn{3}{|c|}{ Annual expansion area $\left(\mathrm{hm}^{2} /\right.$ year) } & \multirow[t]{2}{*}{ 1985-2015 } \\
\hline & 1985-1995 & 1995-2005 & 2005-2015 & \\
\hline Zhoushan & 0.00 & 0.17 & 8.14 & 2.77 \\
\hline Jiaxing & 9.66 & 16.74 & 5.81 & 10.74 \\
\hline Ningbo & 56.95 & 313.70 & 171.94 & 180.86 \\
\hline Taizhou & 6.48 & 85.19 & 184.34 & 92.00 \\
\hline Wenzhou & 109.67 & 47.85 & -12.82 & 48.24 \\
\hline Zhejiang Province & 182.76 & 463.64 & 357.41 & 334.61 \\
\hline
\end{tabular}

the coast, the expansion of S. alterniflora is limited by dikes.

Although undergoing expansion in most regions, $S$. alterniflora has decreased in area in some regions over the past 30 years due to human control efforts, such as in Hangzhou Bay. On the one hand, sediment deposition led to the rapid accumulation of tidal flats outside the dikes, and S. alterniflora expanded accordingly. On the other hand, local residents eliminated S. alterniflora on the tidal flat and transformed the tidal flat into aquaculture ponds.

\section{Uncertainty in monitoring S. alterniflora invasion based on remote sensing}

Due to the limited accessibility of tidal flats, it is difficult to pass through S. alterniflora areas. Field investigations are time consuming and laborious, making it difficult to conduct regional-scale surveys. Remote sensing technology has been widely used in monitoring studies of vegetation dynamics due to its repetitive acquisition of regional-scale images [27, 29]. However, there is still some uncertainty in monitoring the invasion of S. alterniflora based on remote sensing.

Landsat data are the most commonly used data for monitoring vegetation on a regional scale. However, the resolution of the data is relatively coarse $\left(30^{*} 30 \mathrm{~m}\right)$, there are many mixed pixels, and vegetation areas less than $1000 \mathrm{~m}^{2}$ are difficult to distinguish. The edge of S. alterniflora communities is mixed with an S. mariqueter community or mangrove forest, and it is difficult to accurately extract S. alterniflora from remote sensing images. Studies have also used high-resolution images and unmanned aerial vehicle (UAV) images to extract areas of S. alterniflora with high precision. However, the cost of purchasing high-resolution images is high, and much work is needed to extract $S$. alterniflora areas on a regional scale.

Different classification methods also lead to certain uncertainties. It is widely believed that object-oriented 

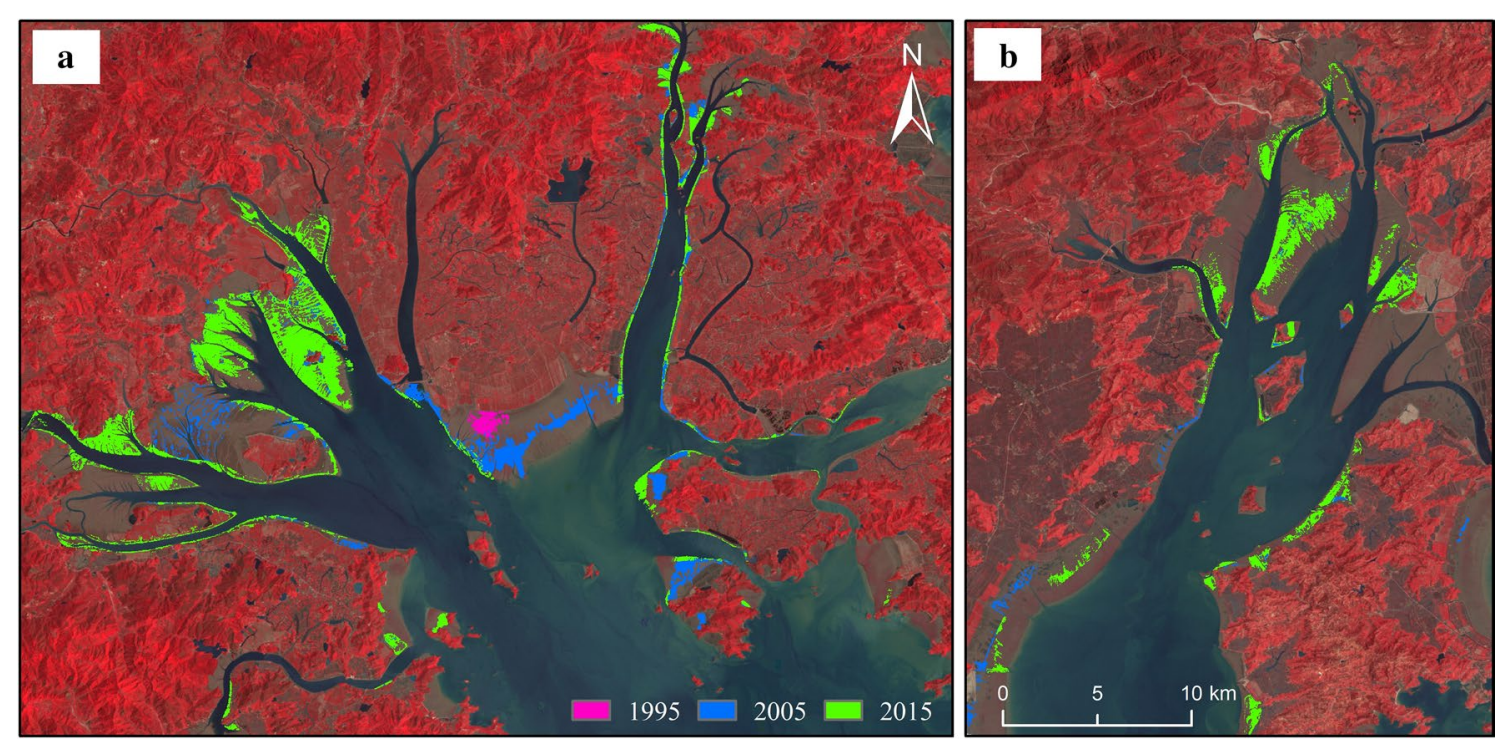

Fig. 4 The expansion of S. alterniflora in Sanmen Bay (a) and Yueging Bay (b). Red, blue and green represent the distribution of S. alterniflora in 1995, 2005 and 2015, respectively
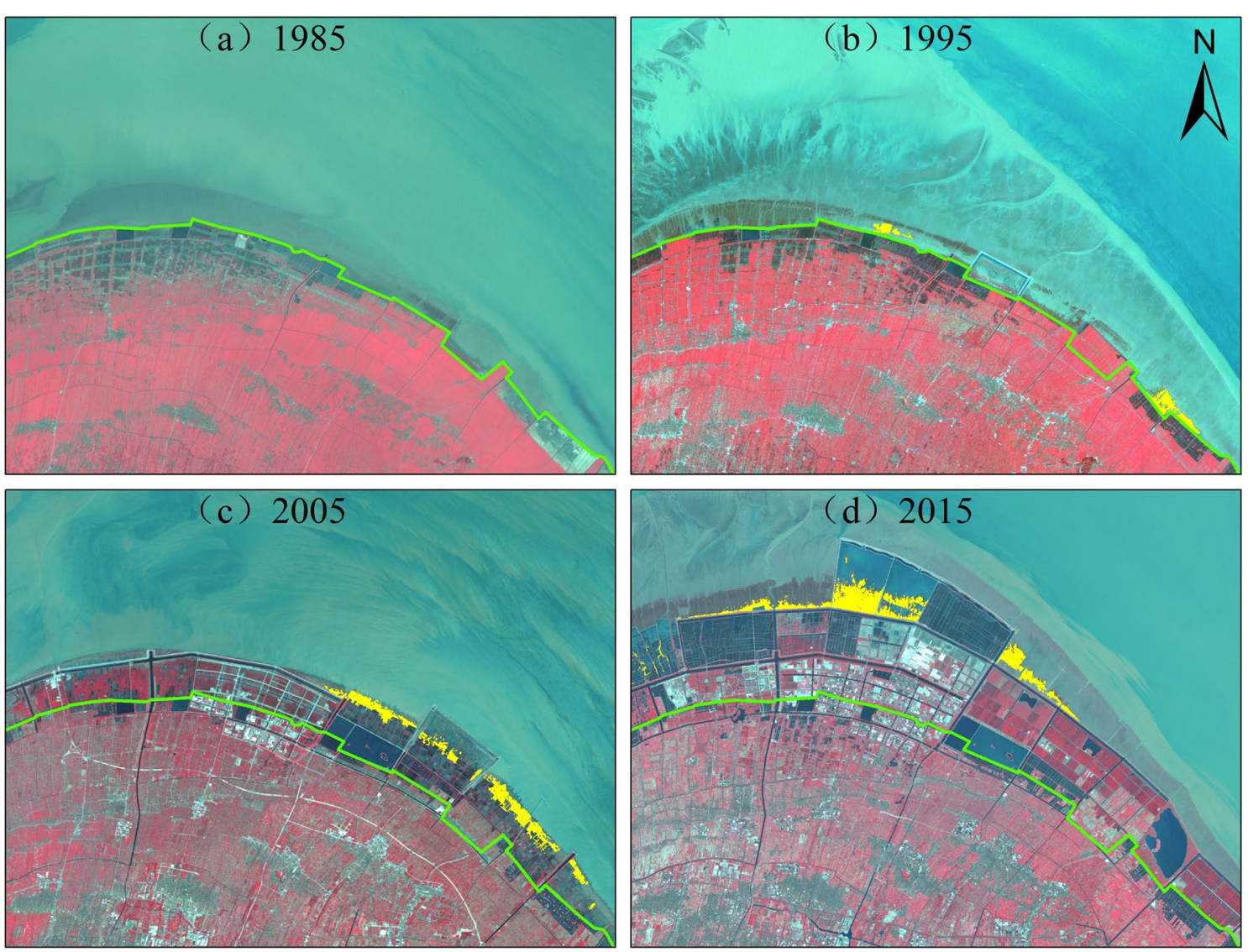

Spartina alterniflora

Coastline in 1985

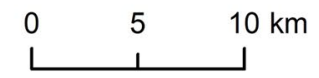

Fig. 5 The expansion of S. alterniflora in Hangzhou Bay in recent decades 


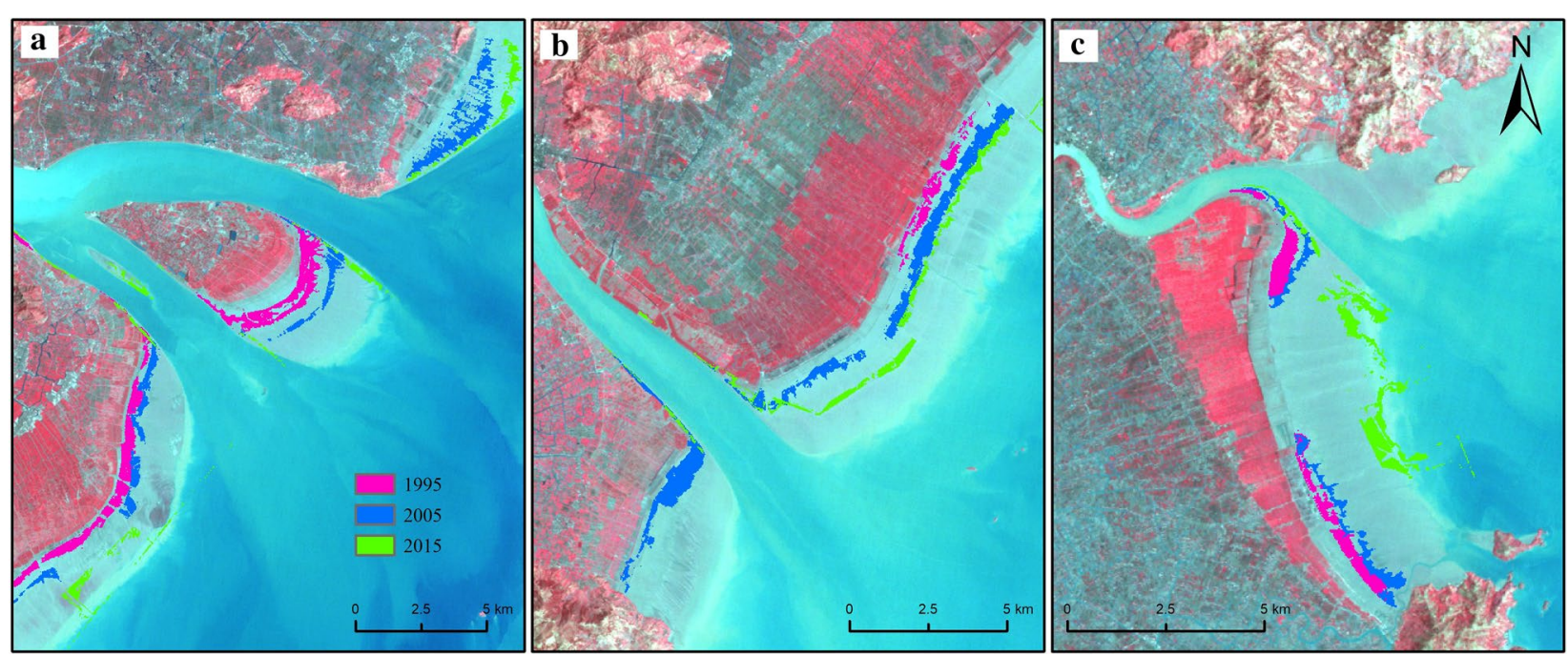

Fig. 6 The expansion of S. alterniflora in the Ou River Estuary (a), Feiyun River Estuary (b) and Ao River Estuary (c). (Red, blue and green represent the distribution of S. alterniflora in 1995, 2005 and 2015, respectively)

methods are more accurate than pixel-based methods, but it is difficult to determine the optimal scale for object-oriented segmentation. Variables such as spectrum, texture, shape, and expert knowledge all contribute to the extraction of $S$. alterniflora and need to be used according to the data and actual conditions.

In addition, tides are an important factor in the uncertainty of mapping S. alterniflora. S. alterniflora was concentrated in intertidal zones that are periodically submerged by seawater, and its area was affected by tidal water. In Fig. 7a, c are images of high-tide periods, when S. alterniflora was almost submerged in tidal water, and (b) and (d) are images of low-tide periods, when $S$. alterniflora grew well and was widely distributed. Remote sensing satellites have a defined visitation cycle and cannot obtain images of the same location every day. For example, the Landsat satellite takes images of the same place every 16 days. At the same time, if the weather conditions are not good, the images covered by clouds are almost impossible to use. When the study area is large (covering multiple scenes) and multiperiod changes are of interest, it is difficult to ensure that the acquired images are from the same low-tide period.

Spartina alterniflora rapidly expanded in tidal flats and was removed in some areas by local residents [12]. Therefore, results for S. alterniflora in the same year vary among studies, as do S. alterniflora mapping results in the same year. Lu et al. [1], Liu et al. [32] and Mao et al. [33] monitored S. alterniflora in China, but their results differed because of the study differences in the types of data acquired and in the study periods. It is difficult to say whose research results are more accurate because
S. alterniflora has been changing dynamically and lacks reliable historical monitoring data. Future research may require more high-resolution data or the use of multiple data sources, as well as new methods such as machine learning, to more accurately monitor the invasion of $S$. alterniflora.

\section{The factors determining the invasion of S. alterniflora}

Many factors affect the invasion of S. alterniflora. According to the literature, we summarize the main factors affecting the expansion of S. alterniflora. First, S. alterniflora has high tolerance to salt, flooding and temperature. S. alterniflora is a typical halophyte, with a salinity suitable for growth of $1 \%$ to $2 \%$; this species can tolerate high salinity of up to $6 \%$. In a saline environment, S. alterniflora adopts a salt-repelling strategy; it can also secrete salt [34]. The leaves of S. alterniflora are densely covered with stomata, and the highly developed aeration tissue transports oxygen to the underground part to relieve the oxygen deficiency caused by flooding [35]. This species can tolerate $12 \mathrm{~h}$ of flooding every day. When low- or high-temperature stress occurs, S. alterniflora can accumulate a large amount of soluble sugars.

Second, this species has a high reproductive capacity. The high seed yield and high germination rate of $S$. alterniflora facilitate its rapid expansion [36]. In addition to undergoing propagation by seed, $S$. alterniflora can grow axillary buds on the nodes of its stem and on underground stems, which can emerge from the soil surface and form new plants under suitable conditions [37]. Clonal reproduction facilitates the maintenance and 

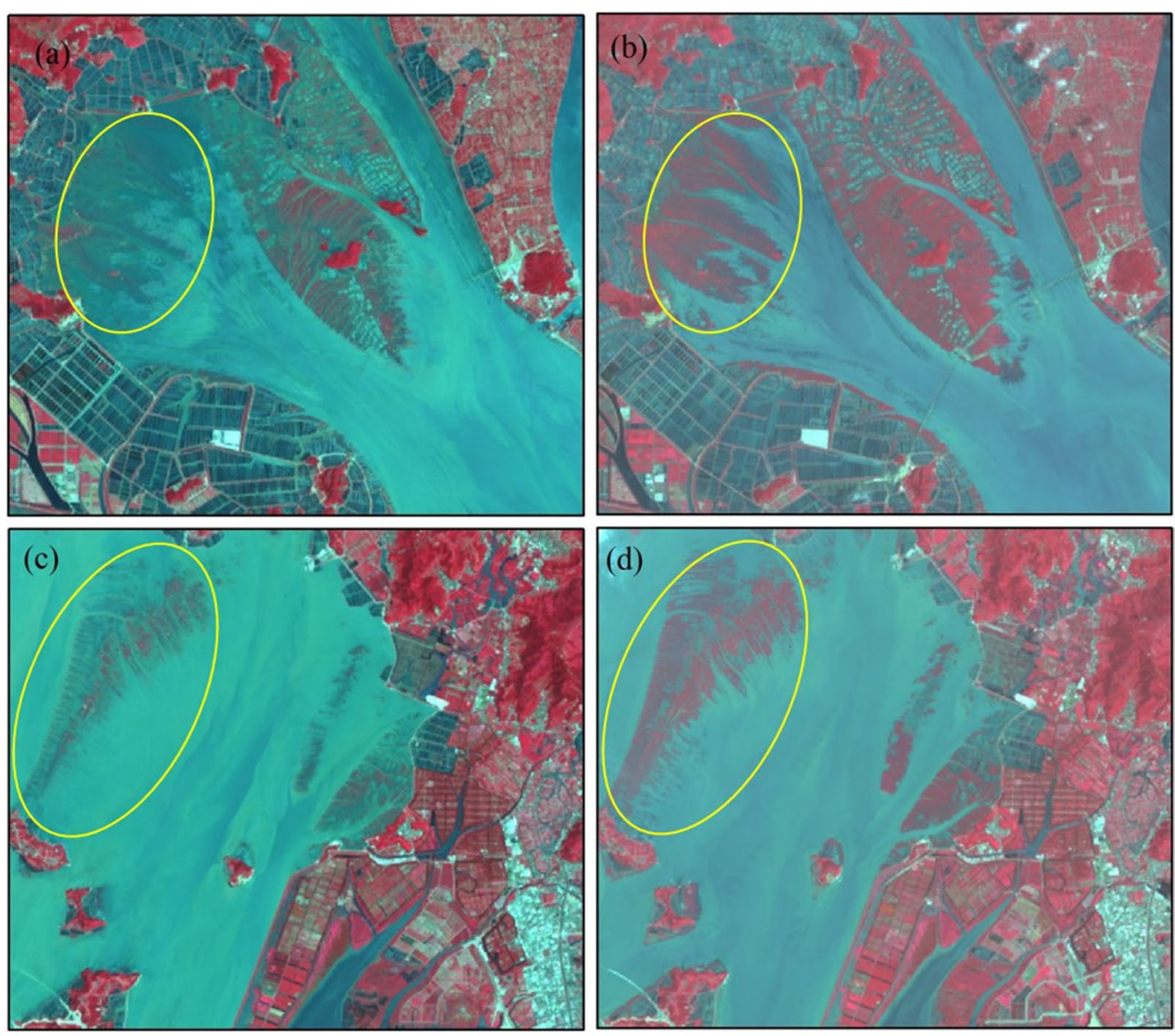

Fig. 7 Remote sensing images of Sanmen Bay (a) and Yueqing Bay (b) under different tide conditions

renewal of populations as well as rapid proliferation and outbreaks [36, 38].

Third, the suitable habitat and lack of natural control mechanisms in this region promote S. alterniflora. There are no special growth requirements in terms of soil, and S. alterniflora can grow in clayey, loamy and silty soils. In China, silt and muddy tidal flats in coastal areas are rich in nutrients and are widespread. The tidal power, geology, climate, soil conditions and seawater salinity in these areas are quite suitable for S. alterniflora growth and reproduction. At present, there are no local, natural enemies that can control the growth and spread of S. alterniflora in the tidal flats of China. The imbalance of natural ecological competition has led to the uncontrolled proliferation of S. alterniflora. Due to the lack of natural control mechanisms, S. alterniflora can rapidly expand due to its strong growth ability [39].

Finally, intentional introduction and natural media promote $S$. alterniflora in this region. S. alterniflora has played an important role in reducing coastal erosion and promoting reclamation, and for this reason, its introduction was extended from Zhejiang, Jiangsu and Fujian Provinces to all coastal areas. Natural media such as tides and winds also influence the dispersal of $S$. alterniflora [40]. In addition, S. alterniflora can be unintentionally transferred through a variety of human activities, such as shipping and certain forms of land transport [39].

Muddy tidal flats are widely distributed along the coast of Zhejiang Province, providing suitable growth environments for S. alterniflora. Summer currents flow from south to north, carrying the plants and seeds of $S$. alterniflora northward. Once S. alterniflora reaches new tidal flats, it can quickly settle and occupy the flats, grow extensively, and invade the native vegetation community.

\section{Conclusion}

The rapid invasion of China's coastal areas by $S$. alterniflora has serious consequences for local ecosystems. Accurate monitoring of the invasion is essential for coastal ecological protection. In this study, we proposed a simple and effective method to map the 
spatial distribution of S. alterniflora in Zhejiang Province in China, using a time series of Landsat images from 1985 to 2015 . The results showed that the total area of S. alterniflora in Zhejiang was approximately $10,038.15 \mathrm{hm}^{2}$ in 2015 and that the species was mainly distributed in bays, such as Hangzhou Bay, Yueqing Bay and Sanmen Bay, and estuaries, such as the Oujiang, Aojing, and Feiyun River estuaries. In recent decades, S. alterniflora has expanded rapidly, with the highest expansion rate between 1995 and 2005, reaching 463.64 $\mathrm{hm}^{2} /$ year. During the invasion from south to north, the extent of expansion varied among regions, with Ningbo exhibiting the greatest expansion. This study provides multitemporal distribution data for the study of $S$. alterniflora invasion in Zhejiang, revealing the temporal and spatial dynamics of the invasion process and helping the government control S. alterniflora.

\begin{abstract}
Abbreviations
S. alterniflora: Spartina alterniflora; TM: Landsat Thematic Mapper; OLI: Operational Land Imager; UTM: Universal Transverse Mercator; NDVI: Normalized difference vegetation index; UAV: Unmanned aerial vehicle; NASA: National Aeronautics and Space Administration.
\end{abstract}

\section{Acknowledgements}

We would like to thank the Priority Academic Program Development of Jiangsu Higher Education Institutions (PAPD) and the Doctorate Fellowship Foundation of Nanjing Forestry University.

\section{Authors' contributions}

$\mathrm{NL}$ and $\mathrm{LL}$ conceived and planned the study, interpreted the results and wrote the manuscript. MW and $Y Z$ provided funding. All authors revised the manuscript. All authors read and approved the final manuscript.

\section{Funding}

This research was funded by the Zhejiang Province-Chinese Academy of Forestry joint-supported Forestry Science and Technology Program (\#2018SY03) and the Postgraduate Research and Practice Innovation Program of Jiangsu Province (KYCX17_0819).

\section{Availability of data and materials}

The datasets generated and analyzed during the current study are available in the Dryad repository at https://datadryad.org/stash/share/b_OmhaXulXQd NvaCnAiWHSwuoyQNi64ws5OI_tbPUfE.

\section{Ethics approval and consent to participate}

No permissions were required for the field surveys.

\section{Consent for publication}

Not applicable.

\section{Competing interests}

The authors declare that they have no competing interests.

\footnotetext{
Author details

${ }^{1}$ Collaborative Innovation Center of Sustainable Forestry in Southern China of Jiangsu Province, Nanjing Forestry University, Nanjing 311300, China. ${ }^{2}$ School of Environmental \& Resource Sciences, Zhejiang Agriculture and Forestry University, Hangzhou 311300, China. ${ }^{3}$ Institute of Subtropical Forestry Research, Hangzhou 311400, China.
}

Received: 14 October 2019 Accepted: 30 January 2020 Published online: 06 February 2020

\section{References}

1. Lu JB, Ying Z. Spatial distribution of an invasive plant Spartina alterniflora and its potential as biofuels in China. Ecol Eng. 2013;52(2):175-81.

2. Chung $\mathrm{CH}$. Forty years of ecological engineering with Spartina plantations in China. Ecol Eng. 2006;27(1):49-57.

3. Chung $\mathrm{CH}$. Thirty years of ecological engineering with Spartina plantations in China. Ecol Eng. 1993;2(3):261-89.

4. Liu JE, Zhou HX, Qin P, Zhou J. Effects of Spartina alterniflora salt marshes on organic carbon acquisition in intertidal zones of Jiangsu Province, China. Ecol Eng. 2007;30(3):240-9.

5. Peng RH, Fang CM, Li B, Chen JK. Spartina alterniflora invasion increases soil inorganic nitrogen pools through interactions with tidal subsidies in the Yangtze Estuary, China. Oecologia. 2011;165(3):797-807.

6. Qin P, Xie M, Jiang YS, Chung CH. Estimation of the ecological-economic benefits of two Spartina alterniflora plantations in North Jiangsu, China. Ecol Eng. 1997;8(8):5-17.

7. Shen YM, Liu YM, Chen QZ. Distributing character of soil organic matter in salt marsh of Spartina alterniflora Loisel. Mar Sci Bull. 2003;22(6):43-8.

8. Wang JQ, Nie ZM. Exotic Spartina alterniflora provides compatible habitats for native estuarine crab Sesarma dehaani in the Yangtze River estuary. Ecol Eng. 2008;34(1):57-64.

9. Wu YT, Wang CH, Zhang XD, Zhao B, Jiang LF, Chen JK, Bo L. Effects of saltmarsh invasion by Spartina alterniflora on arthropod community structure and diets. Biol Invasions. 2009;11(3):635-49.

10. Zuo P, Zhao S, Liu CA, Wang C, Liang Y. Distribution of Spartina spp. along China's coast. Ecol Eng. 2012;40:160-6.

11. An SQ, Gu BH, Zhou CF, Wang ZS, Deng ZF, Zhi YB, Li HL, Chen L, Yu DH, Liu YH. Spartina invasion in China: implications for invasive species management and future research. Weed Res. 2010;47(3):183-91.

12. Li HP, Zhang LQ. An experimental study on physical controls of an exotic plant Spartina alterniflora in Shanghai, China. Ecol Eng. 2008;32(1):11-21.

13. He WS, Feagin R, Lu JJ. Impacts of introduced Spartina alterniflora along an elevation gradient at the Jiuduansha Shoals in the Yangtze Estuary, suburban Shanghai, China. Ecol Eng. 2007;29(3):245-8.

14. Rosso PH, Ustin SL, Hastings A. Use of lidar to study changes associated with Spartina invasion in San Francisco Bay marshes. Remote Sens Environ. 2006;99(3):295-306.

15. Wang RZ, Lin Y, Zhang LQ. Impacts of Spartina alterniflora invasion on the benthic communities of salt marshes in the Yangtze Estuary, China. Ecol Eng. 2010;36(6):799-806.

16. Gan XJ, Cai YT, Chiyeung C, Ma ZJ, Chen JK, Bo L. Potential impacts of invasive Spartina alterniflora on spring bird communities at Chongming Dongtan, a Chinese wetland of international importance. Estuar Coast Shelf Sci. 2009;83(2):211-8.

17. Gao H, Peng XW, Li B, Wu QH, Dong HQ. Effects of the invasive plant Spartina alterniflora on insect diversity in Jiuduansha wetlands in the Yangtze River Estuary. Biodiversity Science. 2006;14(5):400-9.

18. Neira C, Levin LA, Grosholz ED, Mendoza G. Influence of invasive Spartina growth stages on associated macrofaunal communities. Biol Invasions. 2007;9(8):975-93.

19. Callaway JC, Josselyn MN. The introduction and spread of smooth cordgrass (Spartina alterniflora) in south San Francisco Bay. Estuaries. 1992;15(2):218-26.

20. Daehler CC, Strong DR, Carey JR, Moyle P, Rejmánek M, Vermeij GJ. Status, prediction and prevention of introduced cordgrass Spartina spp. invasions in Pacific estuaries, USA. Biol Cons. 1996;78(1-2):51-8.

21. Chen HL, Bo L, Hu JB, Chen JK, Wu JH. Effects of Spartina alterniflora invasion on benthic nematode communities in the Yangtze Estuary. Marine Ecol Progr. 2007;336(12):99-110.

22. Chen ZB, Li G, Jin BS, Wu JH, Zheng GH. Effect of the exotic plant Spartina alterniflora on macrobenthos communities in salt marshes of the Yangtze River Estuary, China. Estuarine Coast Shelf Sci. 2009;82(2):265-72.

23. Wang Q, An SQ, Ma ZJ, Zhao B, Chen JK, Li B. Invasive Spartina alterniflora: biology, ecology and management. Acta Phytotaxon Sin. 2006:44(5):559-88.

24. Guyhaim T, Lyons DA, Kotta J, Ojaveer H, Queirós AM, Chatzinikolaou E, Arvanitidis C, Como S, Magni P, Blight AJ. Diverse effects of invasive ecosystem engineers on marine biodiversity and ecosystem functionsa global review and meta-analysis. Glob Chang Biol. 2017;24:906-24.

25. Lövei GL. Biodiversity: global change through invasion. Nature. 1997;388(6643):627-8. 
26. Sala OE, Wall DH. Global biodiversity scenarios for the year 2100. Science. 2000;287(5459):1770-4.

27. Li N, Lu DS, Wu M, Zhang YL, Lu LY. Coastal wetland classification with multiseasonal high-spatial resolution satellite imagery. Int J Remote Sens. 2018;39(23):8963-83.

28. Zhang RS, Shen YM, Lu LY, Yan SG, Wang YH, Li JL, Zhang ZL. Formation of Spartina alterniflora salt marshes on the coast of Jiangsu Province, China. Ecol Eng. 2004;23(2):95-105.

29. Li N, Li L, Lu D, Zhang Y, Wu MJWE. Management: detection of coastal wetland change in China: a case study in Hangzhou Bay. Wetlands Ecol Manage. 2019;27(1):103-24.

30. Davranche A, Lefebvre G, Poulin B. Wetland monitoring using classification trees and SPOT-5 seasonal time series. Remote Sens Environ. 2010;114(3):552-62.

31. Adler-Golden SM, Matthew MW, Bernstein LS, Levine RY, Berk A, Richtsmeier SC, Acharya PK, Anderson GP, Felde JW, Gardner J: Atmospheric correction for shortwave spectral imagery based on MODTRAN4. In: Imaging Spectrometry V: 1999. International Society for Optics and Photonics: 61-70.

32. Liu M, Mao D, Wang Z, Li L, Man W, Jia M, Ren C, Zhang Y. Rapid invasion of Spartina alterniflora in the coastal zone of mainland China: new observations from Landsat OLI images. Remote Sens. 2018;10(12):1933.

33. Mao D, Liu M, Wang Z, Li L, Man W, Jia M, Zhang Y. Rapid Invasion of Spartina alterniflora in the coastal zone of mainland China: spatiotemporal patterns and human prevention. Sensors. 2019;19(10):2308.

34. Bradley PM, Morris JT. Relative importance of ion exclusion, secretion and accumulation in Spartina alterniflora Loisel. J Exp Bot. 1991;42(245):1525-32.
35. Maricle BR, Lee RW. Aerenchyma development and oxygen transport in the estuarine cordgrasses Spartina alterniflora and S. anglica. Aquat Bot. 2002;74(2):109-20.

36. Deng ZF, Shu Qing A, Zhi YB, Zhou CF, Chen L, Zhao CJ, Fang SB, Li H. Preliminary studies on invasive model and outbreak mechanism of exotic species, Spartina alterniflora Loisel. Acta Ecol Sin. 2006;26(8):2678-86.

37. Sun SM. Monitoring of smooth cordgrass invasion by remote sensing in Sandu Bay, Fujian. J Oceanogr Taiwan Strait. 2005;24(2):223.

38. Deng ZF, An SQ, Zhou CF, Wang ZS, Zhi YB, Wang YJ, Shi SH, Lin C, Zhao CJ. Genetic structure and habitat selection of the tall form Spartina alterniflora Loisel, China. Hydrobiologia. 2007;583(1):195-204.

39. Li B, Liao CZ, Zhang XD, Chen HL, Wang Q, Chen ZY, Gan XJ, Wu JH, Zhao B, Ma ZJ. Spartina alterniflora invasions in the Yangtze River estuary, China: an overview of current status and ecosystem effects. Ecol Eng. 2009;35(4):511-20.

40. Huiskes AHL, Koutstaal BP, Herman PMJ, Beeftink WG, Markusse MM, De Munck W. Seed dispersal of halophytes in tidal salt marshes. J Ecol. 1995;83(4):559-67.

\section{Publisher's Note}

Springer Nature remains neutral with regard to jurisdictional claims in published maps and institutional affiliations.
Ready to submit your research? Choose BMC and benefit from:

- fast, convenient online submission

- thorough peer review by experienced researchers in your field

- rapid publication on acceptance

- support for research data, including large and complex data types

- gold Open Access which fosters wider collaboration and increased citations

- maximum visibility for your research: over $100 \mathrm{M}$ website views per year

At BMC, research is always in progress.

Learn more biomedcentral.com/submissions 